\title{
Effect of the Cascade Injection Molding on the Filling Behaviour
}

\section{Martin Habrman, Karel Ráž, Tomáš Kalina}

Regional Technological Institute, Faculty of Mechanical Engineering, University of West Bohemia, 30614 Pilsen. Czech. E-mail: mhabrman@rti.zcu.cz,kraz@rti.zcu.cz, tkalina@rti.zcu.cz

This paper deals with different ways of injection molding. A plastic part can be generally filled many ways. Use of more than one gate is common in a plastic industry. Cascade molding can affect the final properties of the product, especially by the number of gates, timing of closing - opening and by the order of individual gates. A simple plastic box is used as a reference part in this paper. It is a longitudinal part with one side longer than the others. There are ribs on the bottom side of the box. The injection system is located on the bottom side of the box. The filling process is considering five individual gates. All possible filling variants are compared with respect to temperature, pressure and number of weld lines. Sequential filling from the central point of the box is the most suitable option.

Keywords: Multi-gate Injection Molding, Hot Runner System

\section{Introduction}

There are many software tools which can be used for determination of the best placement for the gate. The gate is place where the melt enters the part. The best placement is not dependent on pressure, temperatures, etc. Even if the best placement for one gate is found, the required parameters on the machine can be too high. Filling by one gate requires very high pressure and this can limit the choice of machines. A better machine is usually more expensive. Generally used way how to solve it is usage of multi - gate filling. More gates can be added into cold or hot runner system. Hot runner system was selected to fill a reference part.

The hot runner system can keep more uniform temperature of the plastic part. Each gate has a constant temperature. This system is more expensive than the cold runner system. The advantages of the hot runner system are lower machine conditions, less waste of material and need for controling of gates. The gate is controlled by a nozzle. The signal for opening or closing the nozzle can be time or melt of front position. A problem is to define the time for opening and closing the gate. Mold flow analysis has

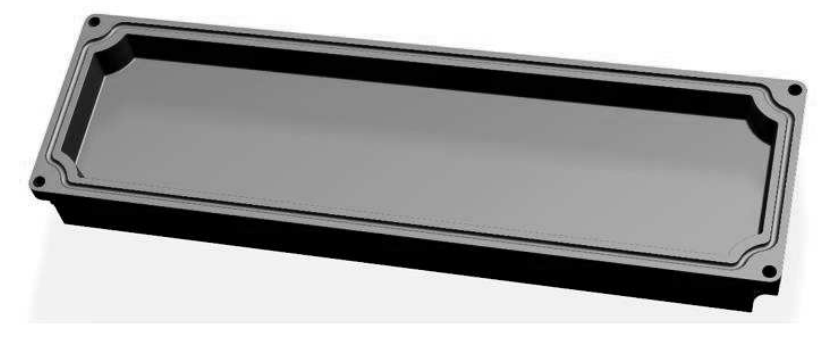

to be performed for this. The melt front control requires the information about the location of the melt from the sensor. The position of front melt gives a signal for controls the gate. It is necessary to find answers to the following questions. On which side of the product to place gates? What will control the gates? In which order will the gates be open. In what order will the gates fill? Is it necessary to use every gate?

The hot runner system is very often to using for part with in one direction longer than other, complicated shape, reduction of injection time, pressure etc.

\section{Description}

A shell-shaped part in the Fig. 1 Model of boxFig. 1 was selected in this research. It is plastic part with ribs, sealing groove and holes for screws. Dimension in the longitudinal direction is longer than in the others. The interior space is designed to store small items. The sealing groove is on the top surface. Holes for screws are in the edge of part. The size of the part is 200x60-17 mm. Material of the box is ABS Polyflam Rabs 90000 UV5 from producment A. Schulman.

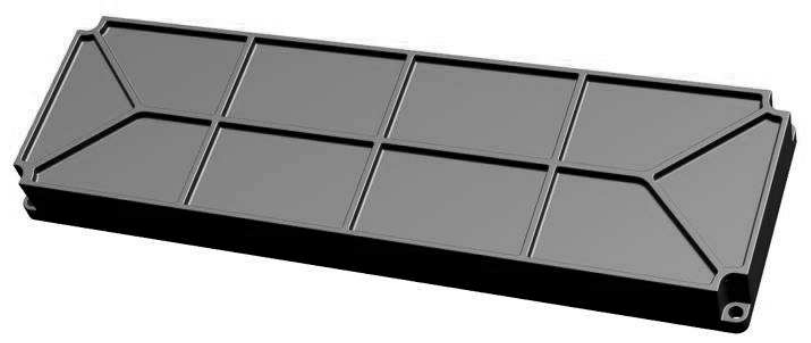

Fig. 1 Model of box

It is important to take into account which side of the plastic box is visible. This site is important for design of the part, because gates would not be located on this side.

The internal surface of box is more important comparing to others. After opening is the first look inside the box. Smooth walls are important for storage of items in the box. The position of the gates is on the surface with ribs, because this side will not be visible during usage of this part. [6]

\section{Injection system}

Injection system is visible in the following figure. The hot runner system has five gates. The plastic material is heated to a melt temperature which is same for all gates. Every gate has a number (1-5) which helps to improve an order in the mold- flow software. 


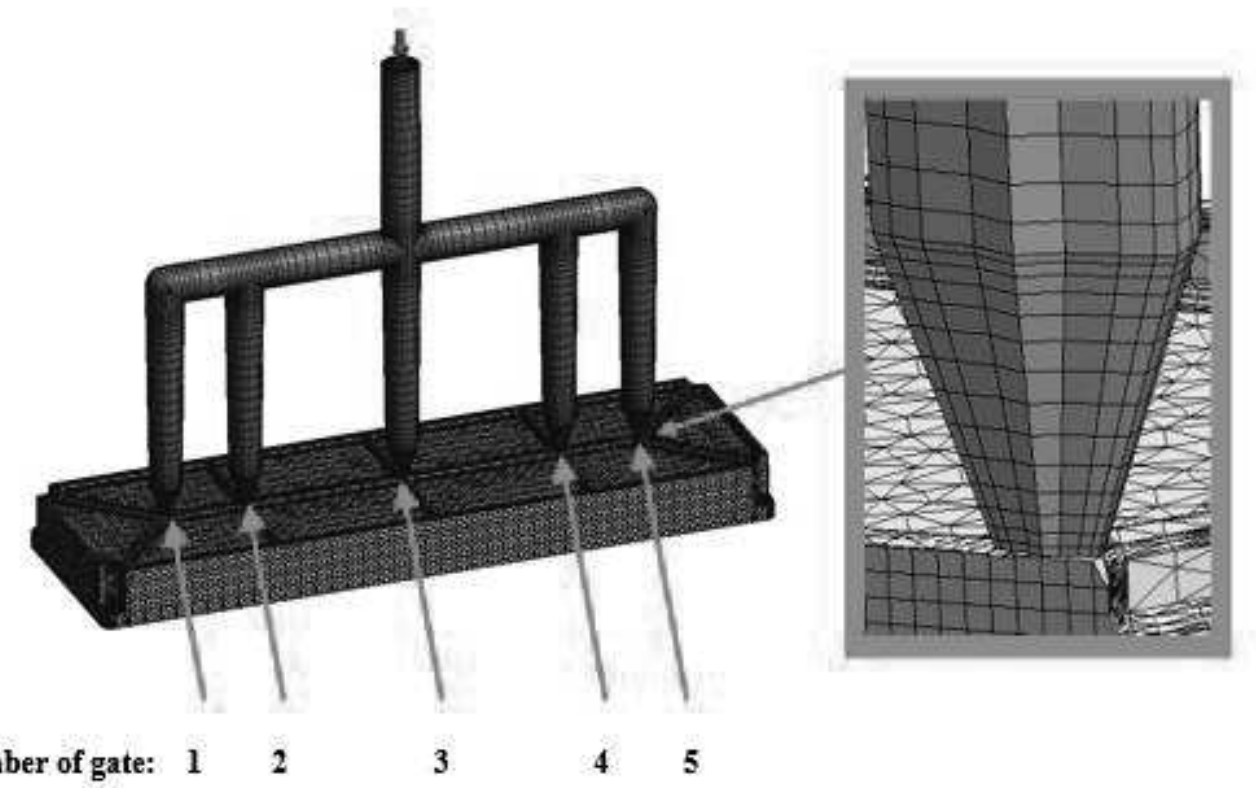

Number of gate: 12

Fig. 2 Injection system and detail of mesh in the cross section

The mesh quality was selected at level three from five in Moldex3D. Density of mesh is visible in Fig. 2. The mesh is denser in the part than injection system. Total number of elemtes is around 350000 . Injection system consist of 41000 elements. [7, 8]

\section{Simulation}



Fig. 3 Variants of filling

For controlling was selected melt front control. Controling by melt front is more complicated than time controlling. The principle is based on usage of sensors of the melt flow in the channels. A sensor gives a signal to control the needle. Sencor gives a signal when the melt front reaches the position sensor. Sensor location was selected at the bottom of the rib - inside of the part. The melt first fills in the bottom surface of the rib and after the melts flows into walls of part. The top of the rib is filled later
Five variants of filling were created, schematically in the Fig. 3. This number is not final, here exist many variants, but the described variants are commonly used. The work contains both controlled and uncontrolled gates. The signal for controlling is the melt front. Two variants use only one gate. These variants are for comparing with sequential opening variants. 
pressure was selected on the end of filling and packing. It means the maximum value in the part. The temperature value is almost the same. The temperature was selected

Tab. 1. [10] on the end of filling and packing too. The comparison of variances value shows in the

Tab. 1 Pressure and temperature of the simulation values

\begin{tabular}{|c|c|c|c|c|c|c|}
\hline \multirow{2}{*}{ Name } & \multirow{2}{*}{ Unit } & \multirow{2}{*}{$\begin{array}{l}\text { All gates par- } \\
\text { allel }\end{array}$} & \multicolumn{2}{|c|}{ From middle } & \multicolumn{2}{|c|}{ From side } \\
\hline & & & 1 gate & Sequential & 1 gate & Sequential \\
\hline Pressure of filling & $\mathrm{MPa}$ & 9.2 & 13.8 & 9.6 & 19.4 & 10.6 \\
\hline Pressure of packing & $\mathrm{MPa}$ & 4.8 & 6.8 & 4.8 & 10.3 & 5.4 \\
\hline Temperature of filling & ${ }^{\circ} \mathrm{C}$ & 240.9 & 244.1 & 240.9 & 245.7 & 241.3 \\
\hline Temperature of packing & ${ }^{\circ} \mathrm{C}$ & 237.3 & 237.4 & 237.1 & 238.9 & 237.6 \\
\hline
\end{tabular}

The biggest pressure differences are between filling from side and other variants. Filling from the side and only one gate requires the greatest pressure. The effect of sequential opening of other gates has reduced the required pressure value by almost half. All gates open required the lowest pressure value. The pressure distribution Fig. 4 is shown in the part crosssection. [11]

\section{All gates parallel}

From middle: $\quad$ One gate (3)

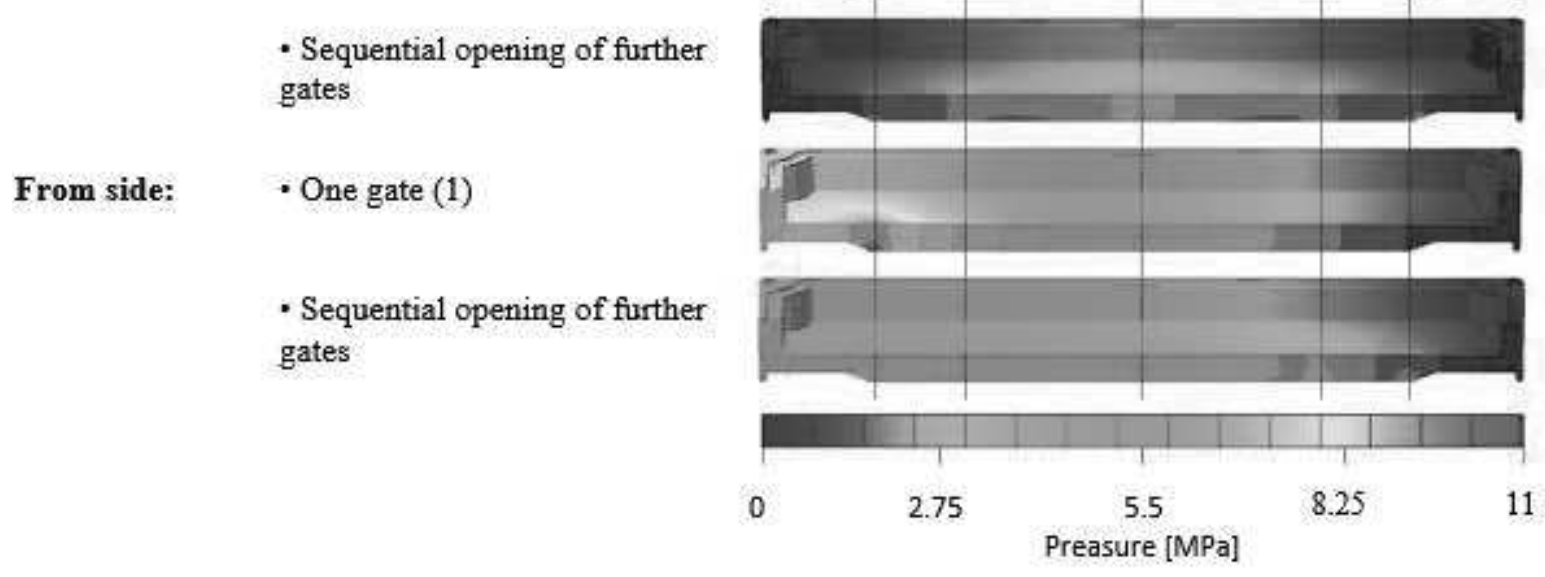

Fig. 4 Comparison of all variants over pressure in the cross section of the part

Multi - gates filling is reducing the required parameters on the machine. The disadvantage of this method is higher number of weld lines. A weld line is formed when two separate melt fronts are joined into one flow. The weld lines are not appropriate for the part, but it is not

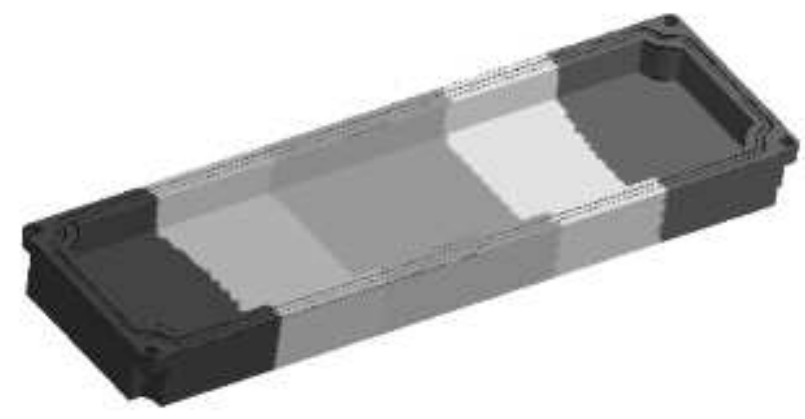

possible to avoid all of them. It is not recommended to place weld lines at positions with higher stress, because mechanical properties are at weld line lower. The worst design with respect to weld lines is parallel filling, Fig. 5. [5]

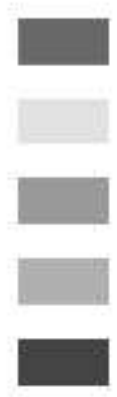

Gate 1 - filling $14.8 \%$

Gate 2 - filling $19.3 \%$

Gate 3 - filling $31.4 \%$

Gate 4 - filling $19.3 \%$

Gate 5 - filling $14.2 \%$

Fig. 5 Filling all gates parallel 




From middle - sequential opening further gates
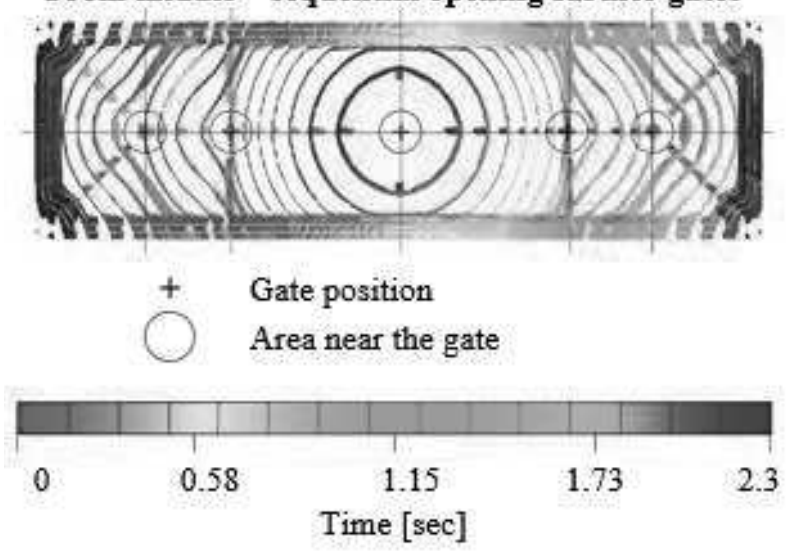

Fig. 6 Comparison of melt front time

Fig. 5 shows gates contribution. The melt with flow through the gate has a specific color. The variant of filling by all has five colors. The color distribution is almost uniform. It is because of that the all gates are open. Weld lines are on the border two colors. Number of these borders is four. The border (weld line) is located across the part. The other weld lines are in corners and other places in the part (same for all variants of filling). In terms of weld lines, there are better variant - filling by one gate or sequential opening further gates. The difference between the two variants is shown in Fig. 6. [9]

Fig. 6 shown melt front time. Comparing of filling is shown in isosurfaces. An isosurface is a surface of the same time within a volume of space. Changes in the isosurface shape shows difference close to gates. The flow of melt is increased close to these gates. The isosurface shows higher velocity of material in the middle of the part. The gates during sequential openening fom middle are opened in followich scheme: 3, 2 and 4 and last is 1 and 5 . The biggest difference between described two variants is close gate one and five. The total comparison of all variants is in the Fig. 7. [1,2]

Comparison of all variants is shown on isosurfaces in the cross section of the part. Representation of filling of all gates parallel can predicting where the weld line will be. Other variants have not that so big weld line. The difference between filling one gate or sequential opening further gates is very good to see. Sequential opening further gates, the isosurface are farther from the start. [3], [4]

\section{All gates parallel}

$\begin{array}{ll}\text { From middle: } & \text { - One gate (3) } \\ & \begin{array}{l}\text { - Sequential opening of further } \\ \text { gates }\end{array} \\ \text { From side: } & \text { - One gate (1) } \\ & \begin{array}{l}\text { - Sequential opening of further } \\ \text { gates }\end{array}\end{array}$
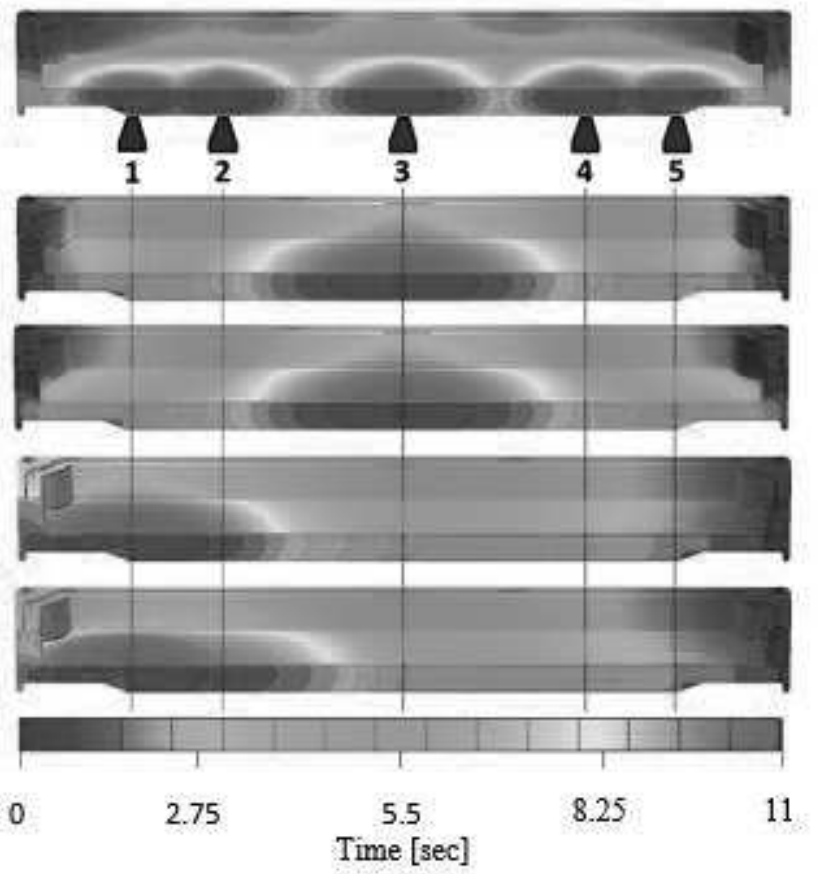

Fig. 7 Comparison of melt front time for all variants in the cross section of the part

\subsection{Evaluation}

In terms of number and distribution of weld lines, the filling of all gates parallel was the worst. Filling only one gate does not have so many weld lines. Their disadvantage is very height required parameters from machine. Filling from the middle less required parameters than filling from the side. Sequential opening of further gates was better. The start of filling was very important. Especially the distance from the start to the end of filling. Filling from the middle has smaller distance than filling from the side.

Filling from the middle with sequential opening of further gates was the best variant. 


\section{Conclusion}

This paper deals with variants of filling. The part and the hot runner system were defined, and they did not change during this work. The variants focused on the possibilities of filling. The best variant was selected from five variants. The number of variants is not final. It is possible to come up with more variants. The goal was to find the best variant of filling. The location of the filling was taken into account. Next the order of filling was solved. It is possible to confirm further recommend. The first filling gate is placed in to the center of the part. If it is possible the sequential opening further gates.

\section{Acknowledgement}

The present contribution was supported from ERDF "Research of additive technologies for future applications in the machinery industry - RTI plus" (No. CZ.02.1.01/0.0/0.0/18_069/0010040).

\section{References}

[1] MARKOVICOVA, L., ZATKALIKOVA, V. (2016). Composite Materials Based on pa Reinforced Glass, Fibers, In: Materials Today: Proceedings, Vol. 3, pp. 1056-1059, E-ISSN:2214-7853

[2] MARKOVICOVA, L., HURLATOVA, L., ZATKALIKOVA, V., GARBACZ, T. (2014). Evaluation of composite structures by light microscopy and image analysis, In: Manufacturing Technology, Vol. 14, No. 3, pp. 351-355, ISSN 1213-2489

[3] KALINA, T.; SEDLACEK, F.; KRYSTEK, J. (2018). Determination of the influence of adherent surface on the adhesive bond strength. MATEC Web of Conferences 157, 14 March 2018, Article number 05012, ISSN 2261236X, DOI: $10.1051 /$ matecconf/201815705012

[4] KALINA, T.; SEDLACEK, F.; KROUPA T. (2018). Determination of cohesive parameters for mode I of epoxy adhesive. Proceedings of the 29th DAAAM International Symposium, pp.0746-0751, B. Katalinic (Ed.), Published by DAAAM International, ISBN 978-3-902734-20-4, ISSN 1726-
9679, Vienna, Austria, DOI:10.2507/29th.daaam.proceedings.108

[5] RUSNAKOVA, S., CAPKA, A., FOJTL, L., ZALUDEK, M., RUSNAK, V. (2016). Technology and Mold Design for Production of Hollow Carbon Composite Parts, In: Manufacturing Technology, Vol. 16, No. 4, pp. 799-804, ISSN 12132489 .

[6] FABIAN, M., BOSLAI, R., IZOL. P., JANEKOVA, J., FABIANOVA, J., FEDORKO, G., BOZEK, P. (2015). Use of Parametric 3D Modeling. Tying Parameter Values to Spreadsheets at Designing Molds for Plastic Injection, In: Manufacturing Technology, Vol. 15, No. 1, pp. 24-31, ISSN 1213-2489.

[7] NHUYEN VO, T., SEIDL, M. (2016). Evaluation of Applicability of Unconventional Cooling Method in Injection Mould, In: Manufacturing Technology, Vol. 16, No. 1, pp. 220-225, ISSN 12132489.

[8] RÁŽ, K., ZAHÁLKA, M., POLÁK, R. (2016) Injection Molding Simulations of Hardly Producible Parts from PBT. In Proceedings of the 27th $D A A A M$ International Symposium. Vienna: DAAAM International, Vol. 16, No. 1, pp. 501505. ISBN: 978-3-902734-08-2, ISSN: 1726-9679

[9] RAZ, K., ZAHALKA, M., CHVAL, Z., KUCEROVA, L. (2017). Analysis of Weld Line Influence on Strength of Nylon Patrs. In: ManufacturingTechnology, No. 4, pp. 561-565. ISSN: 1213-2489

[10] MAREK, V. (2016). Basic research of thermal transfer simulations. 27th International DAAAM Symposium on Intelligent Manufacturing and Automation 2016. ISBN: 978-1-5108-3300-5

[11] RÁŽ, K., CHVAL, Z. (2017) Influences of pressures and cycle times on properties of final plastic product from HDPE. In 2017 International Conference on Mechanical, System and Control Engineering (ICMSC). New York: Institute of Electrical and Electronics Engineers Inc. s. 1-5. ISBN: 978$1-5090-6530-1$ 